\title{
APUNTES SOBRE LA CONSTRUCCIÓN ESTÉTICA KANTIANA TRAS LA MODERNIDAD
}

\author{
Sonia MAURICIO SUBIRANA
}

Resumen: La dialéctica ilustrada resulta fundamental para entender los problemas de la modernidad de los que sigue siendo heredera la estética actual. Este artículo muestra como la construcción de La Crítica del Juicio de Kant, concebida inicialmente como boveda que culminará su edificio racional, incardina a este autor en el proceso de desenmascaramiento ilustrado. Para ello, se utilizan tres fragmentos autónomos que conectan, de forma paralela, el proyecto estético de Kant con la práctica en distintos ámbitos artísticos. Así, en primer lugar se compara la arquitectura kantiana con la utopia constructiva de Piranesi lo que configura un original collage, del que se nutrirá el Romanticismo y el Absolutismo estético de Nietzsche. En el segundo fragmento, el sujeto estético kantiano se pierde en el mismo bosque de luces y sombras que Hamlet lo que permite indagar en la pérdida de certezas con la que pugna la razón ilustrada. Finalmente, en el tercer fragmento se muestra como Kant utiliza la dialéctica ilustrada, a partir del recurso lingüistico de la antinomia, para ofrecer soluciones novedosas a problemas artísticos tradicionales que influirán de forma decisiva en las corrientes bermenéuticas posteriores.

Abstract: The illustrated dialectics turns out to be fundamental to understand the problems of the modernity of which she continues being a heiress the current aesthetics. This article shows as the construction of The Judgment's Critique of Kant, understood initially as vault that will reach his rational building, places this author in a process of unmasking the Illustration. For it, there are used three autonomous fragments that they connect, by parallel form, the Kant's aesthetic project with the artistic practice. This way, first the Kantian architecture is compared with the constructive utopia of Piranesi that forms an original collage, of which there will be nourished the Romanticism and the Nietzsche's aesthetic Absolutism. In the second fragment, the 
aesthetic Kantian subject gets lost in the same forest of lights and shades that Hamlet, it allows to investigate in the loss of certainties with which the illustrated reason conflicts. Finally, in the third fragment it appears as Kant uses the illustrated dialectics, from the linguistic resource of the antinomy, to offer novel solutions to artistic traditional problems that will influence the decisive form of hermeneutic posterior currents.

\section{Introducción}

Pensar, en el sentido de la Ilustración, implica el intento de producir un orden científico unitario y deducir el conocimiento de los hechos de principios, entendidos ya sea como axiomas determinados arbitrariamente, como ideas innatas o como abstracciones supremas ${ }^{1}$. De estos presupuestos parte Kant al definir la filosofía como "la ciencia de la relación de todos los conocimientos con los fines esenciales de la razón humana» y al identificar el conocimiento con el juicio que integra lo particular en el sistema. A su vez, este autor se incardina en el proceso de desenmascaramiento ilustrado ya que las paradojas que percibe en su construcción racional lo conducen a tratar de resolver, desde una nueva óptica, sus limitaciones. A partir de ahí, surge la conciencia certera, aunque no se muestre de forma explícita, de las contradicciones en las que deriva un sistema racional hierático.

En esta línea, Kant concibe La Crítica del Juicio como la bóveda que culminará su edificio racional conectando la razón pura con la práctica. No obstante, a medida que profundiza en la sistematización del juicio estético, se encuentra con más problemas para "poner a la razón de acuerdo consigo misma" y con la imposibilidad de perfeccionar su proyecto inicial. Como explica Marchán Fiz $^{2}$, La Crítica del Juicio sella un compromiso de clausura con el sistema aunque, paradójicamente, «las acrobacias mentales a las que tiene que acudir anuncian un litigio no interrumpido entre la formalización y las fugas que la burlan. Las cisuras o roturas de la red encarnan, si no el drama, sí al menos las perplejidades insinuadas, las inseguridades que ensombrecían a Kant como a cual-

\footnotetext{
1994, p. 129.

2 Vid. MARChAN FIZ, S. "La arquitectónica de la razón y sus violaciones en la Crítica del Juicio" en Del Pensar y su Memoria (Ensayos en homenaje al profesor Emilio Lledo), Ed. UNED, 2002, p. 390.
} 
quiera que repare en el sesgo que toman la experiencia estética y sus derivas, activadas en la vivacidad y versatilidad desveladas en su crítica».

Esta dialéctica en la que se ve inmersa la Ilustración adquiere una importancia crucial al explicar la densa complejidad de los procesos que dieron lugar a la modernidad y de los que sigue siendo heredera la estética actual. Este trabajo profundiza en la cara oculta de dicho pensamiento que surge una vez se franquea el umbral del axioma. Para ello, se utilizan tres fragmentos autónomos, que conectan la construcción estética kantiana con la práctica artística coetánea, ya que ambas se reflectan en planos paralelos. Las tres partes quedan unidas por la misma hebra, que evidencia como la edad de las luces queda imbricada, definitivamente, al juego de sus sombras.

El primer fragmento analiza la arquitectura kantiana y la enlaza con la utopía constructiva de Piranesi para mostrar cómo por las fisuras del proyecto de ambos autores se integran elementos que configuran un collage novedoso, del que luego se nutrirá el Romanticismo y el Absolutismo estético de Nietzsche. En el segundo fragmento, el sujeto estético kantiano se pierde en el mismo bosque de claroscuros que Hamlet. A partir de la metáfora compartida, se indaga en la pérdida de certezas al adentrarse en los territorios en penumbra de la intuición, la imaginación y el sentimiento, para concluir vindicando la fusión entre moralidad y estética como única vía para alcanzar la luz.

Finalmente, el tercer fragmento vuelve a los problemas artísticos ya planteados en La querelle des anciens et des modernes ${ }^{3}$, a los que Kant da solución con la vuelta al lenguaje y, en concreto, a través de la figura de la antinomia. Este recurso de la dialéctica ilustrada hace compatibles las bellezas universales con las relativas, hasta ese momento no conciliables, lo que influirá de forma decisiva en todas las corrientes hermenéuticas posteriores.

\section{El desenmascaramiento de la estructura}

La Crítica del Juicio (Kritik der Urtheilskraft) se publicó por primera vez en 1790. Años antes, el teórico de la arquitectura Marc-Antoine Laugier en Essai sur

3 Vid. VID. Perrault, CH. Parallele des anciens et des modernes en ce qui regarde Les Arts et Les Sciences, Tomos I-IV, ed. Slatkene Reprints, Génova, 1979. 
l'architecture (1753) formula su teoría central respecto a los problemas relativos al estatuto teórico e histórico de la columna, siguiendo los trabajos sobre el racionalismo constructivo realizados por el abad francés Cordemoy ${ }^{4}$.

La defensa de la columna exenta que soporta un arquitrabe recto constituye uno de los emblemas de la arquitectura del siglo XVIII. Se trata de un elemento que remite al modelo ideal, natural, originario y fundacional de la cabaña primitiva. La columna, el arquitrabe y el frontón, derivados de dicha construcción natural, fundamentan el modelo racionalista encaminado a la elaboración de un paradigma para el proyecto y la construcción ${ }^{5}$.

Kant en la Crítica del Juicio también parte de un proyecto que, basándose en principios a priori, con una función análoga a la de las columnas, permita construir un edificio racional. Con este fin comienza por acotar el territorio de emplazamiento y establece que los conceptos, en cuanto se relacionan con objetos, y sin considerar si un conocimiento de los mismos es o no posible, tienen su campo, que se determina solamente según la relación que su objeto guarda con la facultad de conocer en general. La parte de ese campo en la cual un conocimiento es posible constituye el territorio (territorium) para dicho concepto junto con la facultad de conocer que le pertenece ${ }^{6}$. Este territorio sobre el cual se construye la esfera filosófica, tanto en su vertiente teórica como práctica, y desde el que ejerce su legislación, se constituye por el conjunto de los objetos de toda experiencia posible, en cuanto no son considerados más que como meros fenómenos.

A partir de estos presupuestos materiales, levanta la primera columna o principio relativo a los conceptos de experiencia basados en la naturaleza. Dichos conceptos, al fundamentarse en la intuición, se representan no como cosas en sí mismas sino como tales fenómenos. Por ello, esta columna se constituye sobre una base resbaladiza; así lo admite Kant cuando afirma que los conceptos de experiencia no tienen ninguna esfera (sino solamente domicilio) porque, si bien son producidos según ley, no son legisladores sino que las reglas

4 Vid. CordemoY, J.L. Nouveau traité de toute l'architecture, París, 1714; Laugier, M.A. Observations sur lárchitecture, París, 1765, p. 4.

5 Vid. RODRIGUEZ RUIZ, D. "Teorias de la arquitectura en el siglo XVIII", en Historia de las ideas estéticas $y$ de las teortas artísticas contemporáneas, Vol. I, La balsa de la Medusa, Visor, Madrid, 1996, p. 104.

6 Vid. KANT, I. Crítica del juicio, Austral, Madrid, oct. ed., 1999, p. 99. 
fundadas sobre ellos son empíricas, y, por tanto, contingentes. La razón respecto al conocimiento teórico de la naturaleza puede tan sólo extraer de leyes dadas, mediante consecuencias, conclusiones que, no obstante, siguen estando en la naturaleza. En este sentido, el territorio sobre el cual está su esfera y se ejerce su legislación continúa siendo sólo el conjunto de los objetos de toda experiencia posible.

La segunda columna de la facultad de conocer la construye en la esfera del concepto de la libertad. La legislación por medio del concepto de libertad la realiza la razón y es sólo práctica, a diferencia de la legislación anterior del entendimiento de carácter teórico. Entendimiento y razón tienen dos diferentes legislaciones sobre el mismo territorio de la experiencia, sin que les sea permitido colisionar una con otra; ambas esferas están apartadas completamente de todo influjo recíproco por el gran abismo que separa lo suprasensible de los fenómenos. El concepto de la libertad no tiene determinación respecto al conocimiento teórico de la naturaleza. El concepto de la naturaleza tampoco se relaciona con las leyes prácticas de la libertad. Es decir, los principios son teórico-prácticos cuando el concepto que determina la causalidad se refiere a la naturaleza. Por otro lado, dichos principios son morales-prácticos cuando se relacionan con la libertad.

Los conceptos de la naturaleza, con base en todo conocimiento teórico $a$ priori, descansan sobre el entendimiento. Los conceptos de la libertad, que contienen la base de todos los conocimientos prácticos sensibles-incondicionados, descansan sobre la legislación de la razón. Se precisa un puente entre el entendimiento y la razón, dos columnas separadas aunque sustentadas en el mismo ámbito. Kant considera que debe haber un fundamento para la unidad de lo suprasensible que permita el tránsito de la razón pura teórica a la práctica. Éste es el Juicio, sobre el cual hay motivo para suponer, por analogía, que encierra en sí igualmente, si no una legislación propia, al menos su propio principio $a$ priori subjetivo que determina su ley. Dicho principio, sin poseer campo alguno sobre los objetos, puede, sin embargo, tener algún territorio y una cierta propiedad del mismo, para lo cual justamente sólo el tal principio sería valedero ${ }^{7}$.

El juicio proporciona, mediante principios a priori extraídos de la naturaleza, leyes posibles particulares con un substrato suprasensible, determinables

7 Vid. Kant, I. Crítica del Juicio, cit., pp. 102 y ss. 
por medio de la facultad intelectual. A su vez, la razón le proporciona al juicio, por medio de su ley práctica a priori, la determinación y hace posible dicho tránsito de la esfera del concepto de naturaleza a la libertad. La Crítica del Juicio sirve como medio de enlace de las dos partes de la filosofía en un todo. A partir de estos presupuestos se propone Kant justificar su edificio racional y conservarlo dentro de los límites de la legitimidad.

La Critica del Juicio se integra de dos partes: la primera dedicada a la estética y la segunda a la teología. Los juicios teológicos junto con los estéticos se sustentan en el mismo principio: la finalidad. No obstante, existen diferencias entre ambos. En el caso del juicio teológico, la representación de la finalidad es objetiva y material y su fin natural es el objeto de una representación lógica. Por contra, el juicio estético manifiesta una finalidad subjetiva, formal, que excluye todo fin objetivo o subjetivo. Por ello, no cabe duda de que dicho juicio estético hace entrar en juego la forma del objeto, pero la forma es precisamente lo que la imaginación refleja del objeto mismo. Se trata de una pura forma subjetiva de la finalidad que excluye todo fin material determinado ${ }^{8}$.

En la dialéctica del juicio estético, Kant no desdeña el fundamento sensible de dichos juicios y su certera vinculación con la intuición y la imaginación. A su vez, es consciente de que lo poliédrico de los principios estéticos puede subvertir sus a priori, de manera que para legitimarlos, de forma muy aguda, recurre a la antinomia. A través de la dialéctica que atraviesa $L a$ Crítica vincula los principios del juicio del gusto con su exclusiva base sustentada en la forma de la finalidad de un objeto o del modo de representación del mismo. En sus palabras: «Dar un determinado principio objetivo del gusto, según el cual los juicios del mismo pudieran ser dirigidos, comprobados y demostrados, es en absoluto imposible, pues entonces no serían juicios de gusto. El principio subjetivo, a saber, la indeterminada idea de lo suprasensible en nosotros, puede tan sólo ser indicado como la única clave para descifrar esa facultad, oculta para nosotros mismos, en sus fuentes; pero nada puede hacérnosla más comprensible» ${ }^{9}$.

De esta manera, la dialéctica del juicio estético, como último anclaje de la crítica trascendental del gusto, produce un vuelco en la arquitectura kantiana.

8 Vid. Deleuze, G. La Filosofia critica de Kant, Cátedra, Madrid, ed. 1997, pp. 112-113.

9 Vid. KANT, I. Crítica del Juicio, cit., p. 304. 
Y, aunque en un principio dicha construcción se aferra a la necesidad de un formalismo racional hierático, con posterioridad las contradicciones en que se sume Kant para poner a la razón de acuerdo consigo misma la insertan en una nueva estructura. El edificio kantiano a medida que se repliega en las sombras proyectadas por sus columnas, conectándose por la bóveda del juicio estético, se ve inmerso en el proceso de desenmascaramiento propio de la contradicción ilustrada. Esta arquitectura no puede ser ajena al ideal reclamado por $\mathrm{D}^{\prime}$ Alembert y teorizado por Piranesi ${ }^{10}$ por el que la formulación de hipótesis es decisiva para lograr soluciones novedosas. Y, como explica Tafuri, nadie puede pretender que toda hipótesis deba quedar completamente realizada ${ }^{11}$. En este sentido, los paralelismos entre el proyecto de dichos teóricos ilustrados no son casuales.

Piranesi ahonda en el mito y en la tradición de lo clásico, descomponiéndolo hasta el detalle, para hacerlo verosímil en el ámbito de la reconstrucción y de la representación de espacios insólitos, que trabajan con la imagen de lo plural. Su deseo de renovación, la invención que persigue, lo libera de los repertorios formales al uso y recurre al collage como método que recupera los objetos legados del pasado y los renueva al mezclarlos con elementos contemporáneos. En este punto el teórico de la arquitectura exalta la capacidad de la imaginación para configurar utopías y para crear modelos válidos, a partir de una metahistoria que proyecta en el futuro la irrupción de las contradicciones presentes. La columna, como elemento clave de la construcción ilustrada, representa para Piranesi la reducción ornamental y la simplificación que reivindica con una apuesta rotunda por el clasicismo ${ }^{12}$.

También Kant admite la necesidad de connivencia de los nuevos conceptos formales con los cánones clasicistas, sin dejar de reclamar la importancia de

10 Vid. PIRANeSI, J. B. Prima Parte di Architettura e Prospettiva, Roma, 1743; Opere varie di architetture e prospettive, Roma, 1750; Le Magnificenzae di Roma, Roma, 1751; Antichità Romane, Roma, 1756; Il Campo Marzio dell' antica Roma, Roma, 1762.

11 Vid. TAFURI, M. «El arquitecto locos: Giovanni Battista Piranesi, la heterotopia y el viaje, en La esfera y el Laberinto. Vanguardias y arquitectura de Piranesi a los años setenta, Biblioteca de arquitectura, Barcelona, 1984, p. 39.

12 Vid. KANT, I. (Critica del Juicio, cit., p. 157 y ss.) cuando acentúa la conexión entre la simplicidad y los juicios puros: «Pero lo puro, es una especie sencilla de sensación, significa que la uniformidad de la misma no es estropeada ni interrumpida por ninguna sensación extraña, y pertenece sólo a la forma". 
la imaginación, al entender que el concepto de gusto es una facultad de juzgar un objeto en relación con la libre conformidad de sus leyes. La imaginación debe tomarse no reproductivamente, tal como está sometida a las leyes de la asociación, sino como productiva y autoactiva, es decir, como creadora de formas caprichosas de posibles intuiciones.

Piranesi se inventa una nueva Roma, ciudad de los modelos, y la deja vagar entre las ruinas de una memoria agrietada. Kant también presagia la poética de la ruina, del desmoronamiento de un paisaje que luego certificará el Romanticismo. De esta manera, las soluciones kantianas para los dilemas generados en La Crítica del Juicio quedan estrechamente vinculadas a las que Piranesi extrae de la práctica artística ilustrada. En concreto, el fraccionamiento, distorsión, multiplicación y descomposición en Piranesi se enmarcan en la crítica sistemática del concepto de lugar. El mismo proceso conduce a que las contradicciones en que se sume el juicio estético kantiano germinen en una nuevaconstrucción. Desde el momento en que el juicio estético se constituye como principio a partir de la base de la experiencia, la espontaneidad entra en el juego de la facultad de conocimiento y se consuma la grieta del sistema oclusivo anterior.

Foucault señala que el primer desgarro por el que el pensamiento del afuera vio la luz en la Ilustración fue, de modo paradójico, en el monólogo reiterativo (ressassant) de Sade. Y sitúa como contrapuestos a dicho autor a Kant y a Hegel, que habitan en la interiorización de la ley de la historia y del mundo, en un momento en el que se requería dicha construcción de forma imperiosa por la conciencia occidental ${ }^{13}$.

A mi juicio, la literatura libertina de Sade expone en toda su crudeza la crisis de la moral convencional ilustrada. A través de la vía de la aberración, este autor muestra el vacío y la desazón existencial que se producen cuando se opta por la inherencia de lo aberrante en lo real. El escritor es un genial testaferro de la lógica de la perversión de una sociedad en decadencia. De hecho, en $\mathrm{La}$ filosofia en el tocador (1795) o en la póstuma: Los ciento vente días de Sodoma se describe de forma pormenorizada como la transgresión moral, puede justificar la perversión del sistema ya que el quebranto o la violación continuada de una ley no implica su modificación o la apertura a nuevos cambios.

13 Vid. FouCAulT, M. "El pensamiento del afuera», Entre Filosofia y literatura, vol. I, Paidós, Barcelona, ed. 1999, pp. 300 y ss. 
Los planteamientos de La Crítica del juicio difieren de los postulados anteriores pero sería inexacto entender que Kant se detiene en la interiorización de la ley. Si bien, en un principio, a partir de la teología del fin, este autor trata de encontrar la explicación última que engarce en su expresión más perfecta las formas y las categorías fundamentales que unen la razón pura con la práctica. No obstante, se encuentra sobrevenidamente con una situación paradójica: cuanto más quiere perfeccionar su armazón racional respecto a dichas categorías se produce de forma ineludible, aunque soterrada, el corte que modifica la estructura. $\mathrm{Al}$ recurrir a conceptos como la imaginación, la intuición y el sentimiento para conformar el juicio estético, las proposiciones mediatamente seguras se convierten en inmediatamente seguras. Esta operación no supone una renuncia al idealismo trascendental por el que los principios estéticos tienen carácter universal, aunque sean valederos para cada cual, y deben ser educados por la razón. Sin embargo, lo conduce a encontrar un nuevo espacio en el que se despliega la estructura del juicio donde se esquivan sus certezas inmediatas.

Hoy, vistas desde la distancia, las columnas que sostienen la construcción kantiana se divisan erguidas y brillantes, desdobladas desde su primera aparición, jugando desde dentro hacia afuera y viceversa. Sus reflejos, como un espejismo perpetuado del desplazamiento, continúan iluminando el poético paisaje actual de La diseminación ${ }^{14}$ :

Columna en marcha, columna de números, columna-espejo, columna de aire, columna de mercurio, columna de oro: oro en fusión, aleación de marca. «Mi palacio magnifico está construido con murallas de plata, columnas de oro..."

\section{La estética del claroscuro}

Kant inaugura la categoría del sujeto autónomo y le confiere a su estética idéntico estatuto ${ }^{15}$. Dicho sujeto, que se da cuenta de sí mismo y comienza a observarse, toma conciencia de la problemática inherente a su propia contra-

14 Vid. DerRIDA, J. «La columna en La diseminación, Fundamentos, Madrid, ed. 1997, p. 513.

15 Vid. MarChá FIZ, S. La estética en la cultura moderna, Alianza forma, Madrid, últ.ed, p. 41. 
dicción y afirma: «Yo, en cuanto ser pensante, soy, sin duda un sujeto uno y el mismo conmigo en cuanto ser sensible “ ${ }^{16}$. Así, muestra la experiencia interna que encierra el elemento material de la conciencia y la multiplicidad de la intuición empírica, el yo de la aprehensión, indisoluble en su percepción externa de la realidad de los fenómenos estéticos. En este proceso de conocimiento no sólo se reclama la representación, sino también su trascendencia para reconocer la existencia de otra enlazada a ella. Precisamente, lo que en la representación de un objeto es meramente subjetivo, es decir, lo que constituye su relación con el sujeto es su cualidad estética.

El filósofo alemán se declara heredero de la estética inglesa del XVIII que bebe de la práctica artística y literaria de ese siglo. Las novedades que Burke aporta en su tratamiento de lo sublime, fundamentales para su construcción, están íntimamente emparentadas con la obra de Shakespeare y Milton, por lo que no es casualidad que dichos autores ejerzan una influencia notable en Kant ${ }^{17}$.

En particular, los autores citados difícilmente podían acogerse a las canónicas clasicistas hasta entonces dominantes y exigían un marco nuevo en el que ya no cabía el concepto tradicional de belleza. De hecho, Shakespeare representa la voz de la naturaleza cuyo espíritu creador se realiza como genio en el genio. En este sentido, enlaza con Kant y la reivindicación del genio como el talento que da la regla al arte y que trasciende de la regla, por lo que considera al genio como el talento de producir aquello para lo cual no puede darse regla determinada alguna, y no una capacidad de habilidad para lo que puede aprenderse según alguna regla. Por ello, la originalidad debe ser su primera cualidad ${ }^{18}$.

16 Vid. KANT, I. Antropologia, Alianza, Madrid, ed. 1991, p. 22-35.

17 Vid. KANT, I. Observaciones sobre el sentimiento de lo bello y de lo sublime, cit., p. 31, 38 y 44; Burke, E. A Philosophical Enquiry into the Origin of our Ideas of the Sublime and Beautifuh 1756, en segunda edición, 1759 (Versión castellana urilizada: Indagación filosófica sobre el origen de nuestras ideas acerca de lo sublime y lo bello, Madrid, Tecnos, 1987).

18 Vid. KANT (Antropología, Alianza, Madrid, ed. 1991, cit., p. 88) que cita a Shakespeare frecuentemente en sus lecciones y le llama genio, a su vez, hace referencia a Enrique IV al indagar en la imaginación y la fantasía: "Así, cuando al hacer un relato los acontecimientos y pretendidas aventuras brotan de la imaginación como un alud que se precipita y crece, sin perseguir otro provecho que hacerse interesante; como el caballero John Falsfatt en Shakespeare que de dos hombres en traje de frisones había hecho cinco personas antes de terminar su relato". 
Este postulado común de trascender de la regla al uso hace que el sujeto kantiano encuentre su reflejo en muchos pasajes de la obra shakesperiana. $\mathrm{Si}$ nos detenemos en el drama de Hamlet, inmerso en su particular bosque de luces y sombras, e intentando restablecer la verdad en un mundo que le resulta complejo y extraño, pronto se suceden las analogías con el sujeto estético kantiano. En concreto, Kant entra de lleno en el campo de las sombras como ineludibles para la percepción estética, sin duda influido por las corrientes neoplatónicas británicas que recuperan el mito de la caverna (la luz y la sombra) para la Ilustración ${ }^{19}$. En La Antropología, puntualiza ${ }^{20}$ : «Tener representaciones $y$, sin embargo, no ser conscientes de ellas, es algo en que parece haber una contradicción; pues, ¿cómo podemos saber que las tenemos si no somos conscientes de ellas? Esta objeción la hizo ya Locke, que rechazaba, por ello, la existencia de semejantes representaciones. Pero lo cierto es que podemos ser mediatamente conscientes de tener una representación aun cuando no seamos inmediatamente conscientes de ella».

El filósofo considera inabarcables estos terrenos oscuros e íntimamente vinculados a la intuición y a lo sensible frente a los pocos lugares iluminados por el pensamiento en el mapa del espíritu. Al reconocer la inmensidad del campo de visión de dichas representaciones oscuras, se adentra en una faceta desconocida pero, sin duda, vital para la comprensión de su pensamiento: la reivindicación de la imaginación como aspecto ineludible de la práctica artística. En concreto, apunta: «La imaginación gustará aquí de pasear por la oscuridad, y será menester siempre un arte no común, si no se quiere, por evitar el cinismo correr el peligro de incurrir en el ridículo puritanismo" ${ }^{21}$.

El sujeto estético kantiano, de forma paralela a Hamlet, deambula por pasajes extraños sintiéndose también con bastante frecuencia como el juguete de dichas representaciones que no quieren desaparecer aunque el entendimiento las ilumine. Esta ofuscación de los sentidos, según su forma natural o artificial será ilusión (illusio) o engaño (fraus). En este último caso, se fundamenta en el testimonio de los sentidos, aunque gracias al entendimiento se declara imposible.

19 Vid. SHAFTeSBURY. Characteristics of Men, Manners, Opinions, Times 1711, Robertson, Londres, 1900.

20 Vid. KANT, I. Antropologia, cit., p. 26.

21 Vid. KanT, I. Antropologia, cit., p. 28. 
La sensación expresa, lo subjetivo de las representaciones de las cosas externas, es decir, lo material (real) de las mismas así como el espacio, expresan la mera forma a priori de la posibilidad de la intuición sensible y, sin embargo, sirven para el conocimiento del objeto exterior ${ }^{22}$. A su vez, la capacidad de sentir un placer nacido de la reflexión sobre la forma de las cosas (de la naturaleza, tanto como del arte) expresa no sólo una finalidad de los objetos en relación con el juicio reflexionante, conforme al concepto de la naturaleza que tiene el sujeto, sino también al revés, una finalidad del sujeto con relación a los objetos, según su forma y hasta su carácter informe, a consecuencia del concepto de libertad.

La niebla de las representaciones sensibles es anterior al entendimiento y se presenta formando una masa que distorsiona los objetos. En este punto, la estética kantiana realiza una apreciación clave al considerar que los objetos vistos en el crepúsculo o a través de una niebla se ven siempre mayores de lo que son; así se introduce la posibilidad de objetos distorsionados por una oscuridad que impide percibirlos en su auténtica dimensión y, a su vez, se magnifican. Para su explicación, recurre al concepto de lo sublime: lo grande por encima de toda comparación, no sólo referido a objetos sino también a estados anímicos vinculados al yo. La soledad profunda es sublime, pero de una manera terrible. En lo sublime se esconden sombras horribles, duendes y fantasmas. La pesadilla es sublime, es el sueño en donde mora lo oscuro. Lo sublime ha de ser siempre grande, lo bello puede ser pequeño.

En Hamlet, la noche también esconde espantosos fantasmas y criaturas deformes y como cuenta Luciano en la Escena XIV:

Negros designios, brazo ya dispuesto

a ejecutaros, tósigo oportuno,

sitio remoto, favorable el tiempo,

y nadie que lo observe. Tú, extraido

de la profunda noche en el silencio,

atroz veneno, de mortales hierbas

(invocada Proserpina) compuesto;

infectadas tres veces, $y$ otras tantas

22 Vid. Kant, I. Crítica del Juicio, p. 117 y ss; Deleuze, G. La filosofía crítica de Kant, Cátedra, ed. 1997, p. 16. 
exprimidas después, sirve a mi intento;

pues a tu actividad mágica, horrible,

la robustez vital cede tan presto.

Este sentimiento de lo sublime viene acompañado de cierto horror o, en otros casos, de melancolía, pero no puede desprenderse de su particular belleza. "Para lo bello de la naturaleza tenemos que buscar una base fuera de nosotros; para lo sublime, empero, sólo en nosotros y en el modo de pensar que pone sublimidad en la representación de aquélla» ${ }^{23}$. Por ello, trata de calmar el desasosiego que le producen las contradicciones que embaten a su fe ilustrada con la naturaleza. En esta línea, considera que la naturaleza no contiene nada que sea monstruoso (ni espléndido ni horrible): la magnitud aprehendi$\mathrm{da}$ puede ser todo lo aumentada que se quiera, con tal de que pueda ser comprendida por la imaginación en un todo. Monstruoso es un objeto que, por su magnitud, niega el fin que constituye su propio concepto.

De nuevo, retorna al ámbito de la razón lógica para desvanecer aquellas representaciones oscuras que no quieren desaparecer aunque el entendimiento las ilumine. Paradójicamente, y ahí radica su grandeza, vislumbra que el principio de la racionalidad llevado hasta sus últimas consecuencias puede convertir en monstruosos los fantasmas de lo irracional. El monstruo ya ha sido nombrado, no tardarán los románticos en representarlo ${ }^{24}$.

Kant persevera en la búsqueda de la verdad, que debe existir en algún lugar. Esta será la única brújula que difumine la niebla y conduzca a la claridad. En Hamlet también a partir de la negrura se hará la luz. En la noche moran los espectros, pero éstos se desvanecen con el canto del gallo que es: «la trompeta de la mañana, con su altanera garganta de agudo sonido despierta al dios del día; y, ante su aviso, todo espíritu que yerre y vague por el mar, fuego, tierra o aire, regresa a su confín" ${ }^{25}$. Para salir de este escenario brumoso es necesario urdir una estrategia que permita emplear una estudiada oscuridad. La puesta

23 Vid. KanT, I. Critica del juicio, cit., p. 186.

24 Vid. SHELLEY, M. Frankestein, primera ed. 1818. No es casualidad que Shelley al abordar esta obra bajo el seudónimo de Marlow, apunta influencias literarias coincidentes con las de la Crítica del Juicio. En concreto, menciona La Iliada, La Tempestad y El sueño de una noche de verano de Shakespeare, y sobre todo, al igual que Kant, señala como fundamental El paraiso perdido de Milton.

25 Vid. ShAKESPEARE, W. Hamlet, cir., Palabras de Horacio en el Acto I. Escena I. 
en juego del drama shakesperiano reclama el enigma, del que Kant participa. Este instrumento permite al sujeto, a partir de su propia sagacidad, penetrar en lo oscuro para extraer, gracias al entendimiento, la claridad que se encuentra en su propio interior.

El poder de abstraer de una representación, incluso cuando se le impone al hombre por los sentidos, es una facultad mucho más considerable que la de atender; porque demuestra la libertad de la facultad de pensar y la autarquía del alma, que tiene bajo su dominio sus representaciones. Por ello, los sentidos no confunden. A quien ha aprehendido, aunque no haya todavía ordenado una multiplicidad dada, no se le puede decir que confunde ${ }^{26}$.

En Hamlet, se afirma: «sé fiel a ti mismo, y a eso seguirá, como la noche al día, que no podrás ser entonces falso para nadie». Dicha coherencia, vinculada al ideal de justicia y moral, es la única antorcha que puede salvar al sujeto. Hamlet, aunque camina entre espectros y sombras, tiene clara su verdad y persigue el desenmascaramiento de la mentira. Para ello, trata de que su madre se arrepienta de sus pecados execrables y vuelve a la técnica del espejo interpuesto. Éste hace saltar a la vista las partes escondidas de quién en él se refleja y le impone: "No te irás hasta que te ponga delante un espejo en que te veas la parte más secreta de ti misma" ${ }^{27}$. El espejo será el instrumento que irradiará la verdad que la hace cómplice del fratricidio por el que ha muerto su marido — símbolo de todo valor y orden-, casándose con el asesino. El sentimiento moral hace sentir un rechazo natural por la maldad, que mora en la sombra, y debe salir a la luz para el restablecimiento del bien.

En la misma línea, concluye la primera parte de La Critica del Juicio reivindicando la fusión entre moralidad y estética como única vía para alcanzar la luz. La belleza se constituye como símbolo de la moralidad. Como el gusto supone una facultad de juzgar la sensibilización de ideas morales (por medio de una cierta analogía de la reflexión sobre ambas), y como de esa facultad, así como de la mayor receptividad que en ella se funda para el sentimiento (llamado moral) de esas ideas morales, se deriva el placer que el gusto declara valedero para la humanidad en general y no sólo para el sentimiento privado de cada cual, resulta que la verdadera propedéutica para fundar el gusto es el

26 Vid. KANT, I. Antropologia, cit., p. 21-38.

27 Vid. SHAKESPEARE, W. Hamlet, cit., Escena XXVII y XXVIII. 
desarrollo de ideas morales y la cultura del sentimiento moral, ya que sólo cuando la sensibilidad es puesta de acuerdo con éste, puede el verdadero gusto adoptar una determinada e incambiable forma.

Al término del drama de Shakespeare la búsqueda de la verdad y la venganza del mal se pagan con la propia vida de Hamlet. La duda como expresión última del claroscuro continúa como eje del drama y persiste incluso después de la muerte del príncipe. $Y$ aunque, en principio, pueda parecer que el sujeto estético kantiano culmina iluminado por la fe ilustrada, disipadora de todas sus vacilaciones, al final vuelve a coincidir con Hamlet en que no puede más que rendirse ante la evidencia de la luz de la duda ${ }^{28}$.

\section{La dialéctica de lo bello kantiano}

Kant reivindica el arte por el arte, es decir, la autonomía artística, y la desvincula de los fines prácticos con el concepto de satisfacción desinteresada. Por ello, abre las puertas a la gran revolución artística que le sucedería. Como explica Marchán $\mathrm{Fiz}^{29}$, aunque es notorio que se nutre de influencias reconocibles al deslizarse a través de los hilos conductores de la autonomía de la estética recién conquistada por el intelectualismo de Baumgarten, G.F. Meier y Sulzer o por el empirismo inglés, lo innovador de su aportación radica en que las categorías anteriores las somete a crítica y las sitúa en las antinomias embarazosas que aquéllos habían alentado pero no resuelto.

La Crítica del Juicio se fundamenta en que el arte es susceptible de perfeccionarse en su empeño por alcanzar el ideal de belleza. Sin embargo, no termina de desechar el empirismo de la crítica del gusto y el racionalismo de la misma que conduce al idealismo de la naturaleza y del arte. Y realiza una síntesis entre los sentidos y el conocimiento a partir del juicio estético de reflexión, que se proyecta sobre la representación dada, y del juicio estético-patológico, cuyo ámbito reside en la práctica artística.

La relación en la determinación de un objeto como bello se enlaza con el sentimiento de un placer que, mediante el juicio de gusto, es declarado vale-

28 Vid. KanT, I. Critica del Juicio, cit., p. 242.

29 Vid. MARCHÁN FIZ, S. La arquitectónica de la razón y sus violaciones en "La Crítica del Juiciom, cit., p. 391. 
dero para cada cual y conduce a que la universalidad de la satisfacción se represente en un juicio de gusto sólo como subjetivo. La capacidad universal de comunicación del estado espiritual, en la representación dada, es la que tiene que estar en la base del juicio de gusto como subjetiva condición del mismo y encuentra, como consecuencia, el placer en el objeto. El fundamento de dicho estado del espíritu radica en el libre juego de la imaginación y entendimiento ${ }^{30}$. No obstante, la influencia que tiene una representación mediante ese sentimiento en la actividad de las facultades del espíritu no es suficiente para explicar el juicio estético. Es necesario recurrir a la idealidad de los objetos que, al percibirse como fenómenos, explica la posibilidad de que sus formas puedan ser determinadas a priori. Para ello, Kant vincula el ideal del arte a la belleza libre, la finalidad sin fin, propia tanto de un organismo como de una obra de arte. Como apunta Gadamer ${ }^{31}$, ello se corresponde con una de las más antiguas definiciones que existen de lo bello en el arte, la de Aristóteles en La Ética a Nicómaco: «Una cosa es bella si no se le puede añadir ni quitar nada».

Por ello, resulta lógico que Kant, al buscar la belleza en el fenómeno, se incline hacia la belleza derivada de la naturaleza que considera no sometida a reglas artificiales. Como por ejemplo, el canto mismo de los pájaros «que no podemos reducir a reglas musicales, parece encerrar más libertad y, por tanto, más alimento para el gusto que el canto humano mismo dirigido según reglas musicales" ${ }^{32}$. La finalidad en el producto del arte bello, aunque es intenciona$\mathrm{da}$, no debe parecer intencionada. El arte bello debe ser considerado como naturaleza, por más que se tenga conciencia de que es arte. En esta línea, un producto del arte aparece como naturaleza cuando alcance toda la precisión en la aplicación de las reglas, según las cuales «el producto puede llegar a ser lo que debe ser, pero sin esfuerzo, sin que la forma de la escuela se transparente, sin mostrar una señal de que las reglas las ha tenido el artista ante sus ojos y han puesto cadenas a sus facultades del espíritu" ${ }^{33}$.

El idealismo de la finalidad es la única suposición por medio de la cual la crítica puede explicar la posibilidad de un juicio de gusto que exige a priori

30 Vid. Kant, I. Critica del juicio, cit., p. 148 y 149.

31 Vid. GADAMER. H. G. La actualidad de lo bello, Introducción de Rafael Argullol, Paidós, ICE-UAB, Barcelona, 1991, p. 106.

32 Vid. KANT, I. Crítica del Juicio, cit., p. 182.

33 Vid. KANT, I. Crítica del Juicio, cit., p. 261. 
validez para cada cual. Ello conlleva aceptar el relativismo del juicio estético que desmonta principios previos (el juicio de gusto descansa en fundamentos «a priori») y demuestra la imposibilidad de su formulación según regla alguna universal. La universalidad de la satisfacción es representada en un juicio de gusto sólo como subjetiva y adelanta el concepto romántico de fragmentación, básico para la construcción posterior de las vanguardias. Pero sería incompleto detener la crítica del Juicio estético kantiano en su radical subjetivismo.

A mi juicio, la originalidad de su planteamiento radica en dar solución a los problemas artísticos ya planteados en la querelle des anciens et des moderns. Frente a discusiones previas respecto a la primacía de las bellezas universales o absolutas, vigentes para el gusto en todos los tiempos, y las bellezas particulares o relativas, que sólo placen o interesan en determinadas épocas ${ }^{34}$ Kant logra demostrar la validez de dos postulados hasta ese momento aparentemente inconciliables.

Por un lado, se sitúa al lado de Les modernes y defiende los atractivos de lo primitivo y lo sublime que vitalizan los referentes artísticos novedosos, contraponiéndose a los modelos refrendados, con presupuestos revolucionarios, basados en que no puede haber regla objetiva alguna del gusto que determine, por medio de conceptos, lo que sea bello. Así, todo juicio emanado de aquella fuente es estético, es decir, que su fundamento de determinación es el sentimiento del sujeto, y no un concepto del objeto ${ }^{35}$.

$\mathrm{Y}$, por otra parte, retorna al clasicismo, a la nostalgia del orden perdido, en nombre del bons sens, buscando la luz en la armonía y la simetría de la belleza. Para Kant, la regularidad en que consiste la simetría debe expresar la unidad de la intuición que acompaña al concepto de fin y con él pertenece al conocimiento. En estos casos, se ha de desarrollar un libre juego de las facultades de

34 La discusión setecentista, que nutrió la literatura artística francesa, situaba entre los modernos a Charles Perrault, Fontenelle y Saint-Evremont que defendían la idea de que el arte es susceptible de perfeccionarse en su empeño por alcanzar el ideal de belleza, lo que genera apreciaciones relativistas. Por otro lado, los tradicionalistas Jean de La Bruyère, Boileau y Fénelon mantenían que el perfeccionamiento se hacía posible por la emulación de los modelos de la Antigüedad clásica. (Vid. PerRaULT, CH. Parallèle des anciens et des modernes en ce qui regarde Les Arts et Les Sciences, cit.; MARCHAN FIZ, S. La estettica en la cultura moderna, cit., p. 17-25; ARNALDO, J. "Ilustración y enciclopedismo", en Historia de las ideas estéticas y de las teorias artisticas contemporáneas, vol. I, cit., p. 69-70).

35 Vid. KanT, I. Crítica del Juicio, cit., p. 167. 
representación (con la condición de que en ello no sufra el entendimiento ningún choque) y han de evitarse los adornos y toda clase de instrumentos artísticos excesivos que se presentan forzados respecto a los principios anteriores ${ }^{36}$.

Ahí, radica la novedad de La Crítica del Juicio, que tiende un puente entre extremos aparentemente inconciliables por medio de la dialéctica del juicio estético. El juego del lenguaje con la figura de la antinomia se resuelve con la posibilidad de que dos proposiciones que se contradicen una a otra en la apariencia no se contradigan en realidad sino que puedan coexistir juntas, aunque la explicación de la posibilidad de su concepto esté por encima de nuestra facultad de conocer.

A partir de dichos presupuestos, la gran apuesta de La Crítica radica en la coexistencia dialéctica de formas aparentemente opuestas ${ }^{37}$, lo que sitúa a la obra artística dentro de un esquema para todas las realizaciones posibles. La mera forma de la finalidad en la representación, mediante la cual un objeto nos es dado, en cuanto somos concientes de ella, puede constituir la satisfacción que juzgamos, sin concepto, como universalmente comunicable, y, por tanto, como el fundamento de determinación del juicio de gusto.

La forma no es objeto de la inspiración o de un esfuerzo libre de las facultades del espíritu, sino de un retoque lento y minucioso para hacerla adecuada al pensamiento y no perjudicar a la libertad en el juego de las facultades. Sin embargo, no se puede prescindir del principio vivificante del espíritu de la obra estética, ligado al potencial de la imaginación que se rige por sus leyes analógicas y de asociación ${ }^{38}$.

Por medio de una primera antinomia, Kant logra la connivencia de la forma con la ausencia de reglas predeterminadas hieráticas que, de constituirse en principios inmutables, conducirían a un academicismo formal que el filósofo rechaza como presupuesto estético. A partir de este razonamiento, matiza que la adaptación a dichas reglas es inconsciente en el arte. La determinación del arte como creación del genio y la cogenialidad del receptor son

36 Vid. KanT, I. Crítica del Juicio, cit., p. 181.

37 Vid. MARCHAN FIZ, S. La estettica en la cultura moderna, cit., p. 47.

38 Vid. KANT, I. Ctítica del Juicio, cit., p. 271. "Las formas que no constituyen la exposición de un concepto dado, sino sólo expresan, como representaciones adyacentes de la imaginación, las consecuencias allí enlazadas y el parentesco con otras, llámanse atributos (estéticos) de un objeto cuyo concepro, como idea de la razón, no puede ser expuesto adecuadamente». 
dos reglas que coexisten y se alteran: la artificial propia de la obra y la natural propia del autor. Genio es el talento (dote natural) que da la regla al arte. Como el talento mismo, en cuanto es una facultad innata productora del artista, pertenece a la naturaleza; podría expresarse así: genio es la capacidad espiritual innata (ingenium) mediante la cual la naturaleza da la regla al arte.

De acuerdo con una segunda antinomia, hace concurrir el uso estético del juicio para el sentimiento de placer y dolor con la idealidad de la finalidad de lo bello. Así, lo bello no puede ser juzgado según conceptos, sino según la disposición de la imaginación conforme a un fin, para la concordancia con la facultad de los conceptos. Por ello, resulta que no es una regla ni un precepto, sino lo que en el sujeto es sólo naturaleza. Pero, a la vez, no se puede negar que el idealismo de la finalidad en el juicio de lo bello de la naturaleza y del arte es la única suposición por medio de la cual la crítica puede explicar la posibilidad de un juicio de gusto que exige a priori validez para cada cual.

Al fin, se concilia la libertad formal con la regla innata vinculada estrechamente a la imaginación y la intuición del autor, de acuerdo con su relación con la genialidad. Por otro lado, gracias a la antinomia se hace compatible el principio del relativismo artístico con referentes de belleza universal. Por todo ello, Kant se estatuye como un clásico y a la vez con un claro carácter innovador, fundiendo ambos conceptos en uno. Y La Crítica del Juicio, tras el paso de la modernidad, sigue siendo una obra abierta, poliédrica e innovadora que da respuesta a múltiples cuestiones que siguen vigentes en el ámbito estético y artístico actual. 